Creativity Research Journal, 2016, Vol. 28, No. 3, 348-356

\title{
EMOTIONAL CREATIVITY AND REAL-LIFE INVOLVEMENT IN DIFFERENT TYPES OF CREATIVE LEISURE ACTIVITIES
}

\author{
Radek Trnka ${ }^{1,2}$, Martin Zahradnik ${ }^{3}$, Martin Kuška ${ }^{1}$ \\ Affiliations: \\ ${ }^{1}$ Prague College of Psychosocial Studies, Prague, Czech Republic \\ ${ }^{2}$ Charles University in Prague, Czech Republic \\ ${ }^{3}$ Charles University Environment Center
}

This is the final version of the manuscript, the Version of Record of this manuscript has been published and is available at https://www.tandfonline.com/doi/abs/10.1080/10400419.2016.1195653

\begin{abstract}
The role of emotional creativity in practicing creative leisure activities and in the preference of college majors remains unknown. The present study aims to explore how emotional creativity measured by the Emotional Creativity Inventory (ECI; Averill, 1999) is interrelated with the real-life involvement in different types of specific creative leisure activities and with four categories of college majors. Data were collected from 251 university students, university graduates and young adults (156 women and 95 men). Art students and graduates scored significantly higher on the ECI than other majors. Humanities scored significantly higher than technical/economic majors. Five creative leisure activities were significantly correlated with the ECI, specifically, writing, painting, composing music, performing drama, and do-it-yourself home improvement.
\end{abstract}

Overall creative capacities are related to various emotional variables, especially to stable emotional characteristics. The significance of stable emotional characteristics is recognizable in experimental creative tasks (Gutbezahl \& Averill, 1996), divergent thinking tasks (Zenasni \& Lubart, 2008) as well as in creative artistic performance (Agular-Vafaie \& Runco, 2008). Ma (2009) classified three main areas of general creativity in his extensive meta-analysis: (a) creativity with less evaluation, including nonverbal and verbal; (b) creativity in problem solving, with more evaluation; and (c) emotional creativity.

Emotional creativity (EC) is a pattern of cognitive abilities and personality traits related to originality and appropriateness in emotional experience (Ivcevic, Brackett, \& Mayer, 2007). It involves the particularly effective application of an already existing emotion or, at a more complex level, the modification of a standard emotion to better meet the needs of the individual or group (Averill, 1999). Divergence from the ordinary emotional experience is a key feature of EC, because EC involves the ability to diverge from the common and generate novel emotional reactions (Ivcevic, Brackett, \& Mayer, 2007). The theoretical conceptualization of EC within other related creativity constructs was previously provided by Gutbezahl and Averill (1996). The most common measurement of EC is a self-report questionnaire, the Emotional Creativity Inventory (ECI; Averill, 1999) developed by James R. Averill. 
Previous empirical research examined, for example, the relationship between EC and a closely related construct, emotional intelligence (Ivcevic, Brackett, \& Mayer, 2007). A series of statistical tests as well as confirmatory factor analyses supported the distinction between emotional and cognitive creativity abilities. Whereas emotional intelligence requires convergent thinking and solving emotional problems, EC requires divergent thinking and generation of an appropriate, as well as original, response. Ivcevic, Brackett and Mayer (2007) specified EC in terms of generation of personalized combinations of emotions. "Emotional creativity can involve a manipulation and transformation of experience that leads to problem solving in the domain of emotions, but experience alone, rather than problem solving, is sufficient for a response to be considered emotionally creative." (p. 228).

Zenasni and Lubart (2008) examined the relation of EC to the creative potential of undergraduate students. Participants performed two divergent thinking tasks, specifically the "unusual uses of a box" test from the Torrance Tests of Creative Thinking (Torrance, 1976 in Zenasni \& Lubart, 2008) and the fictitious situation task concerning traffic (Abele, 1992). "Unusual uses of a box" test is focused on the ability to generate as many unusual uses as possible for a cardboard box. In the fictitious situation task, participants had to imagine what would happen if there was no traffic in their city, and to generate as many unusual ideas as they could. EC did not play a significant role in these creative performances.

Different results were yielded when doing other creative tasks. Gutbezahl and Averill (1996) tested the relationships of narrative creative potential and drawings with EC. In Study 1, participants wrote about three emotionally significant events: (a) an event that occurred at the time they were starting college, (b) a serious love relationship or intense crush that they had experienced, and (c) an unspecified (open-ended) but unusual event, either real or imagined. Only creativity scores for the love narrative were significantly correlated with EC. Further, participants drew crayon pictures of 5 emotions: anger, joy, desperation, hope, and shyness. The drawings were analyzed in two creative domains: expressionistic and pictographic. The expressionistic factor includes the number of colors and their creative use, creative use of space, and complexity of drawings while the pictographic factor comprises figurativeness, use of words, and narration of a story. The pictographic factor corresponded more to a literal representation of the emotion depicted. Participants who scored high on the ECI were more expressionistic than participants who scored low on the ECI. High-scoring participants showed more creative use of color and space, and they were likely to use symbolic (nonfigurative) representations of emotions. On the other hand, participants who scored low on the ECI were more pictographic, they were more likely to rely on figurative forms and to tell a story through the picture.

Another written task and creation of a collage were used in Study 2 of the same paper (Gutbezahl \& Averill, 1996). Participants wrote the conclusion to a story involving a specific emotional conflict (two dormitory roommates who dislike each other). Further, participants were instructed to create a collage of three emotions, joy, anger, and despair, from pieces of paper of various colors, shapes, and sizes. The composite creativity score for the story was correlated with EC, but the composite creativity score for the collage was not.

Ivcevic, Brackett, and Mayer (2007) used the Remote Associates Test (Shames, 1994 in Ivcevic, Brackett, \& Mayer, 2007) to test the ability to make connections between distant ideas. Participants were presented with three words and asked to respond with a fourth word that connects the three stimuli. They also conduct the American Haiku task (Amabile, 1985), writing a five-line, non-rhymed poem according to specific instructions. The assessed novelty of word choice and overall creativity of the poem were positively correlated with EC. Furthermore, only one of four subscales of Averill's (1999) Emotional Creativity Inventory (subscale Novelty) was correlated with the Remote Associates Test. 
The results of the above outlined experiments indicated what cognitive creative abilities are related with EC and what cognitive creative abilities work probably independently of EC. Some studies also tested the relationship of EC with self-report measurements of cognitive creativity. For example, the Creativity Styles Questionnaire-Revised (Kumar \& Holman, 1997) was administrated to university students in the study by Fuchs, Kumar, and Porter (2007). EC was measured by the Emotional Creativity Inventory (Averill, 1999) and correlated with the Creativity styles questionnaire. It seems that cognitive and emotional creativity are partly overlapping constructs when measured by self-report instruments. Authors pointed out that cognitive creativity typically occurs within an interpersonal context, and from this view cognitive and emotional creativity may involve similar skills, or attitudes. However, they also stressed the role of individual differences. "Some individuals may be more technique-oriented in the way they deal with interpersonal situations, whereas others may be more spontaneous and rely on unconscious process, and still others may use strategies based on superstition." (Fuchs, Kumar, \& Porter, 2007, p. 242). It is reasonable to suppose that cognitive creativity, although primarily concerned with intellectual abilities, does involve an emotional investment, as well as the ability to work in interpersonal contexts. On the other hand, it is not likely that EC does not include any intellectual cognitive processing.

Besides the field of creativity research, previous studies have explored many other aspects of EC. EC has been tested in relation to cognitive intelligence (Averill \& ThomasKnowles, 1991; Ivcevic, Brackett, \& Mayer, 2007), Big Five personality traits (Averill, 1999, Study 3; Ivcevic, Brackett, \& Mayer, 2007), self-esteem (Averill, 1999, Study 4), alexithymia (Averill, 1999, Study 5; Fuchs, Kumar, \& Porter, 2007; Zenasni \& Lubart, 2008), authoritarianism (Averill, 1999, Study 4), leadership preferences (Humpreys, 2008), social desirability (Averill, 1999, Study 1), religious orientation (Averill, 1999, Study 4), locus of control (Averill, 1999, Study 4), ways of coping (Averill, 1999, Study 4), peer evaluation (Averill, 1999, Study 2), prior traumatic experiences (Averill, 1999, Study 6), solitude (Long, Seburn, Averill, \& More, 2003), dispositional emotional expressivity (Zenasni \& Lubart, 2008), or in relation to change of the participant's actual emotional state (Zenasni \& Lubart, 2008). Despite previous research, many questions remains unanswered. For example, little attention has been given to educational and leisure domains.

\section{Creativity and Field of Study}

Students of business, humanities and social sciences, and science and technology were tested in verbal divergent production, creative personality traits, and self-reported creative products (Cheung, Rudowitz, Yue, \& Kwan, 2003). Verbal divergent production involved five tasks, which generated measures of divergent thinking as verbal fluency, flexibility, novelty, innovativeness, and originality. Students of humanities and social sciences scored higher in terms of originality and fluency in verbal divergent production, whereas students of science and technology scored higher in verbal innovativeness.

Charyton \& Snelbecker (2007) compared specifically engineering and music students by various creative measures. Musicians had higher levels of general creativity as well as higher levels of music creativity than engineers. No significant difference was found in terms of scientific creativity.

Similarly, self-rated creativity, divergent thinking, and everyday creative achievement of art and science students were compared in a study by Furnham, Batey, Booth, Patel, and Lozinskaya (2011). Art students scored higher in self-rated creativity and also in creative achievement, meaning involvement in various creative activities in the past 12 months (such as writing a short story, composing a piece of music, creating one's own website, designing and planting a garden, etc.). 
As seen above, previous research of cognitive creativity revealed interesting findings in respect to different college majors. This field remains, however, unexplored in the case of EC. Although Sánchez-Ruiz, Hernández-Torrano, Pérez-González, Batey, and Petrides (2011) examined the relationship between trait emotional intelligence, creative cognitive abilities, and self-reported creative personality scale, to our knowledge, no study explicitly concerned with the relationship between EC and student's fields of study has been conducted. Addressing this gap was one of incentives for conducting the present study.

\section{The Present Study}

As mentioned above, little is known about the relationship of field of study and EC in university students. Given the results of previous studies in cognitive creativity research, it seems tenable to hypothesize that levels of EC may vary in different college majors. The present investigation aimed to explore how the choice of college majors is interrelated with EC in the sample of university students.

The previous study by Ivcevic, Brackett, and Mayer (2007) explored the relationship of EC with behavioral creativity that was measured by the Artistic Activity and Artistic Expression and Appreciation Scales (Brackett, 2003 in Ivcevic, Brackett, \& Mayer, 2007). Authors concluded that EC is an ability that significantly predicted involvement in the arts and that EC may play a role in the involvement in self-initiated artistic activities. They also pointed out that the relationship between EC and creative behavior could be better understood by conducting further research focused on real-life creative activities. The present study followed this line of research and aimed to find out what kinds of particular leisure creative activities are related to EC. Such findings were not included in the study of Ivcevic, Brackett, and Mayer (2007), because the authors worked only with two general variables focused on the involvement in performing visual arts and creative writing. The Artistic Activity and Artistic Expression and Appreciation Scales includes two general scales, the Artistic Activity scale and the Artistic Expression and Appreciation scale. The Artistic Activity scale includes items referring to visual arts and creative writing and the Artistic Expression and Appreciation scale is focused on involvement in performing arts and cultural events (e.g. attending an opera or ballet performance). However, the range of real-life creative involvement is much larger and covers plenty of various types of creative activities and hobbies. To our knowledge, no study has explored interrelations of EC and real-life involvement in specific creative activities. Therefore, the present study was focused on the appraisal of relationships of EC with different types of real-life creative activities and creative hobbies as well as to consider gender differences in EC.

\section{Participants}

\section{METHOD}

Data were collected from university students, university graduates and young adults of similar age. The majority of participants were young people, often college students $(68 \%$, age between 18 - 33), educated mostly in the humanities $41 \%$ (technical or economic 29\%; natural science or medicine 9,6\%). The final sample consisted of 251 respondents (156 women and 95 men), the median age was 26 years. Participants were recruited from Czech universities of different types and from random data collection in the capital of the Czech Republic. Participation in the study was fully voluntary and anonymous with no explicit incentives provided for participation. 


\section{Instruments}

\section{Emotional Creativity Inventory}

EC was measured by the self-report questionnaire, the Emotional Creativity Inventory (ECI; Averill, 1999). This ECI version consists of 30 items, rated on a 5-point scale, with anchors of 1 (strongly agree) and 5 (strongly disagree). The total sum range is from low 30 to high 150. Two of the 30 items are reversely coded. The ECI has three subscales that reflect several aspects of EC: preparedness (e.g. I think about and try to understand my emotional reactions), novelty (e.g., I sometimes experience feelings and emotions that cannot be easily described in ordinary language), and effectiveness/authenticity (e.g., My emotions help me achieve my goals in life).

Cronbach's Alpha of the 30-item scale (based on 232 cases) was .89. The total score on the 30-item ECI scale (rated from 1 to 5, respectively sum from 30 to 150) was from 59 to 145 with mean value 99.67. Such a result corresponds well to the literature (Averill's 1999 analysis of 489 respondents sample with range from 59 to 145 and mean of 103.46). The scale thus shows a high degree of internal consistency and allows us to explore the relation between EC and leisure activities.

\section{Real-life involvement in creative leisure activities}

Considering free time activities, seven creative leisure activities were included as options with a 3 -point scale assessing the frequency of its practicing $(1=$ often, $2=$ sometimes, $3=$ never). The proposed leisure activities were: writing poems or prose, including blogs; composing music or music improvisation; performing drama or dance improvisation; drawing pictures or other fine art activities; sculpture or ceramics designed originally by the respondent; any kind of inventing; do-it-yourself, and "any other" category to catch possible left behinds and explore respondents' subjective interpretations of creative activity. The category "any other" was an open question, respondents were allowed to name another creative leisure activity in case that they did not find the appropriate category in the proposed options. The numbered list of the creative leisure activities is provided in the Result section.

The open question "any other creative leisure activity?" was transformed from a 3-point scale into a dichotomous variable: if any additional activity was reported, then it was categorized as presence, when no activity was added, it was considered as absence of additional creative hobby. The decision about whether an activity is creative or not was left to respondents, except in the case of sports. Sports and outdoor activities was a category of their own.

We avoided offering options involving only passive participation in arts like visiting the theatre, or semi-creative activities like playing a musical instrument by reading notes. All the creative leisure time battery was transformed into one dichotomous variable providing information about the presence or absence of any creative activity (if there was presence of value 1 and 2 in at least one of the variables in the battery = presence; if all were rated $3=$ absence).

\section{Field of study}

Students sorted their field of study into four main categories: arts, humanities, natural science/medicine, and technical/economics. The arts category included solely artistic fields of study (such as acting, film making, painting, music, dance, etc.) in accordance with the approach taken by Hartley and Greggs (1997). 


\section{Reliability Analysis}

\section{RESULTS}

There are three dimensions of the ECI scale considered in the literature: preparedness, novelty and effectiveness/authenticity (Averill, 1999). Factor analysis allowed us to consider three factors. Explained variance by the first three factors $(26 \%, 10 \%$, and $5 \%$; see Table 1) corresponded quite well with Averill's $(26 \%, 11 \%$ and 3.f. 6\%), but a more appropriate solution appeared to take into account only one factor and consider the ECI scale as one dimensional.

When the three factor solution was tested, the best options proposed by Factor analysis did not match the theoretical assumptions. Items loaded to factors across the expected structure regardless of the application of Varimax (see Table 2) and/or Oblimin rotation (which was used by Averill 1999 and which confirmed the theoretical structure). Also Cronbach's Alpha reduced from .89 to .75 , resp. .72 when the three dimensions were tested. Therefore the ECI scale was applied primarily as one dimensional in subsequent analysis.

Table 1. ECI Scale - Total Variance Explained

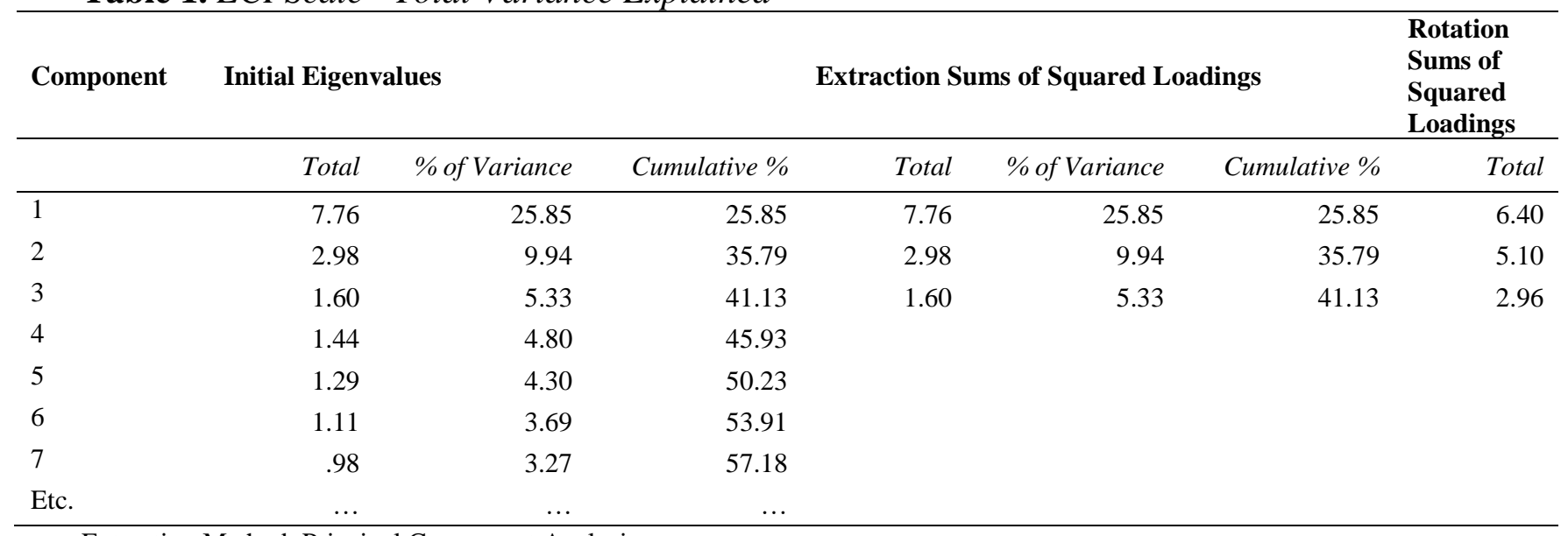

Extraction Method: Principal Component Analysis.

When components are correlated, sums of squared loadings cannot be added to obtain a total variance.

\section{Gender Differences in EC}

The hypothesis about women displaying generally higher EC was tested before going into leisure time details. Statistical tests (Mann Whitney and t-test) proved that women scored significantly higher on the ECI than men (see Table 3 ). The population sample confirmed the hypothesis about more "emotionally creative" women. This finding is in line with previous empirical research (Averill, 1999).

\section{Popularity of Individual Creative Leisure Activities}

The popularity of particular creative leisure activities among students with respect to gender differences is presented in Figure 1 (number of respondents who reported practicing the activity "often" or "sometimes"; total number of women is 156, men 95): fine arts and doit-yourself were the most popular creative leisure activities. Inventing was very popular among men (second place while women place it as fourth). Ceramics and sculpture creating were reported rarely. On one hand, gender differences are visible in ceramics and drama which appear to activities preferred by women while music and inventing are activities preferred by men. On the other hand, when the numbers to equal weight of men and women were standardized, the majority of creative activities were equally distributed between both genders (Figure 2). 
Table 2. ECI Scale- Rotated Component Matrix (Varimax)

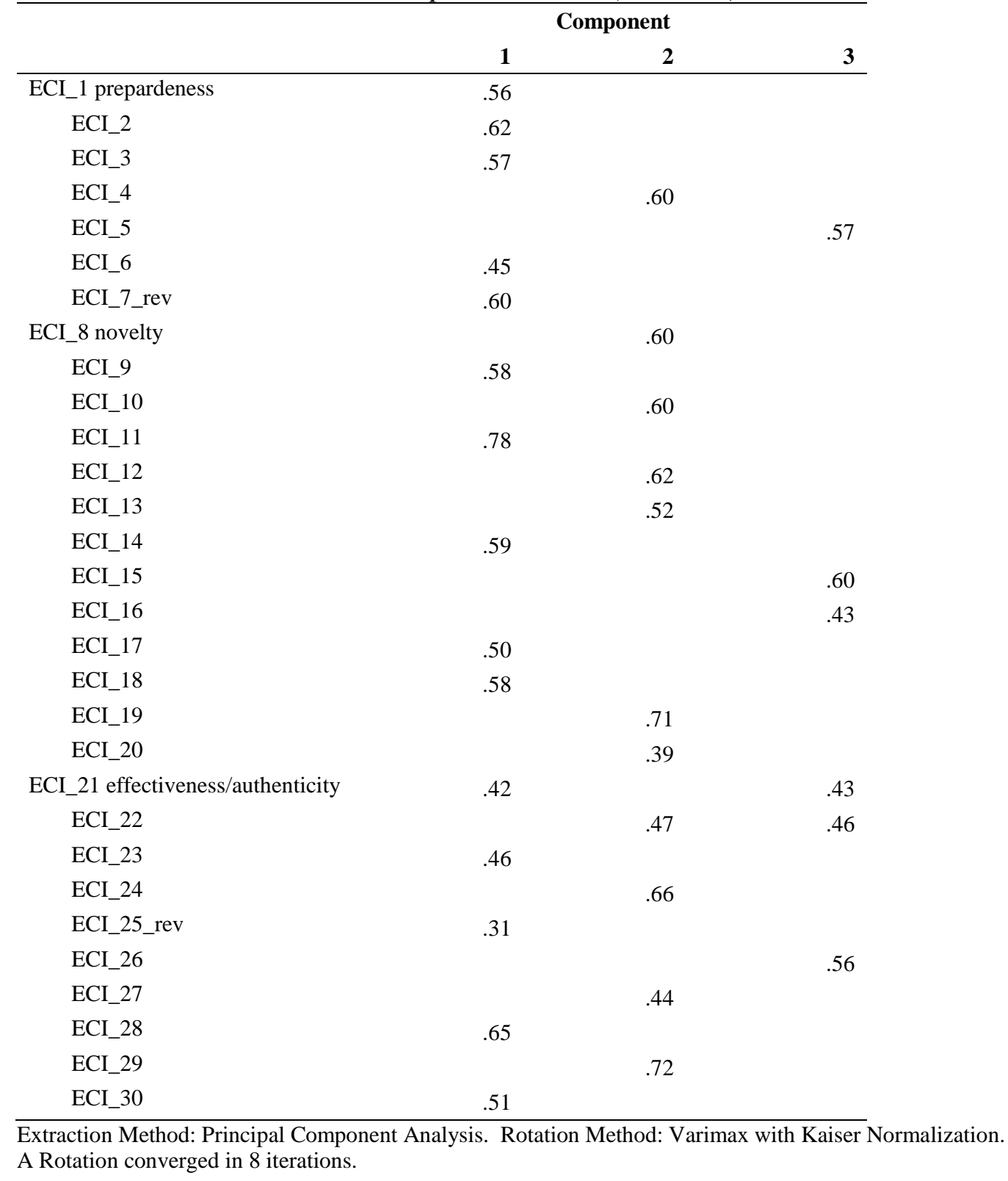

\section{EC and Real-Life Involvement in Creative Leisure Activities}

First, the general relationship between the practice of any creative leisure activity with the ECI score was found. Correlations between ECI and creative activities were tested primarily by Pearson's coefficient, secondly by Kendall's tau-b and Spearmen's rho.

Almost everyone has at least some kind of creative leisure activity. Only 9 of the 251 respondents referred to no such activity at all and they scored significantly lower on the ECI scale (see Table 4). Not surprisingly, real-life involvement in creative leisure activities and the ECI were strongly correlated (correlation $\mathrm{r}=.187$ is significant on $p=.01$ ).

Looking in more detail, five of the seven proposed types of creative hobbies were found to be significantly correlated positively with the ECI score, specifically: 
(1) writing poems or prose, including blogs $(\mathrm{r}=.326, p=.01)$

(2) painting: drawing pictures or other fine art activities $(\mathrm{r}=.251, p=.01)$

(3) DIY: do-it-yourself $(\mathrm{r}=.196, p=.01)$

(4) drama: performing drama or dance improvisation $(\mathrm{r}=.144, p=.05)$

(5) music: composing music or music improvisation $(\mathrm{r}=.141, p=.05)$

Table 3. ECI scores of men and women

\begin{tabular}{llrrrr}
\hline & Sex & $\boldsymbol{n}$ & Mean & SD & SE Mean \\
\hline \multirow{2}{*}{ ECI_sum } & Women & 142 & 102.09 & 15.24 & 1.28 \\
& Men & 90 & 95.86 & 19.70 & 2.08 \\
\hline
\end{tabular}

Table 4. Real-life involvement in creative leisure activities

\begin{tabular}{llrrrr}
\hline & H_dich & $\boldsymbol{n}$ & Mean & SD & SE Mean \\
\hline \multirow{2}{*}{ ECI_sum } & NO creative activity & 9 & 83.56 & 14.66 & 4.89 \\
& YES creative activity & 223 & 100.32 & 17.15 & 1.15 \\
\hline
\end{tabular}

Table 5. ECI scores in different college majors

\begin{tabular}{lcccr}
\hline ECI_sum & $\boldsymbol{n}$ & Mean & SD & SE Mean \\
\hline Arts & 14 & 111.14 & 15.84 & 4.23 \\
Humanities & 94 & 102.09 & 14.88 & 1.53 \\
Natural sciences / Medicine & 22 & 96.59 & 13.44 & 2.87 \\
Technical / Economics & 67 & 95.82 & 19.16 & 2.34 \\
\hline Total & 197 & 99.98 & 16.82 & 1.20 \\
\hline
\end{tabular}

The overall involvement in selected creative leisure activities from a gender perspective is equal (523 activities chosen by men and 526 activities chosen by women). No relation between the popularity of a specific creative leisure activity and higher ECI score of women was found. There was positive correlation between people who refer to additional creative leisure activities and their ECI score $(\mathrm{r}=.187$, significant on $p=.05)$.

An interesting list of additional creative activities was identified which can provide useful tool for follow up research. Besides those creative activities which can be included in the proposed categories (DJing and singing into the music category $3 \mathrm{x}$; dancing into drama $4 \mathrm{x}$; diary, essay and other writing in the writing category $3 \mathrm{x}$; furniture reconstruction and nesting box construction in do-it-yourself $2 x$ ), the respondents reported:

sewing / knitting 11x

photography / film making $7 \mathrm{x}$

jewelry making $6 \mathrm{x}$

gardening, garden design, plant growing $6 \mathrm{x}$

cooking $4 \mathrm{x}$

activities with children (inventing and creating their leisure activities, including creation of fairytales) $3 \mathrm{x}$

flower arrangement $2 \mathrm{x}$.

and single occurrence of items like: creating strategies in PC and top desk games, architecture, thinking, marketing, managing events. 
Figure 1. Popularity of individual creative leisure activities

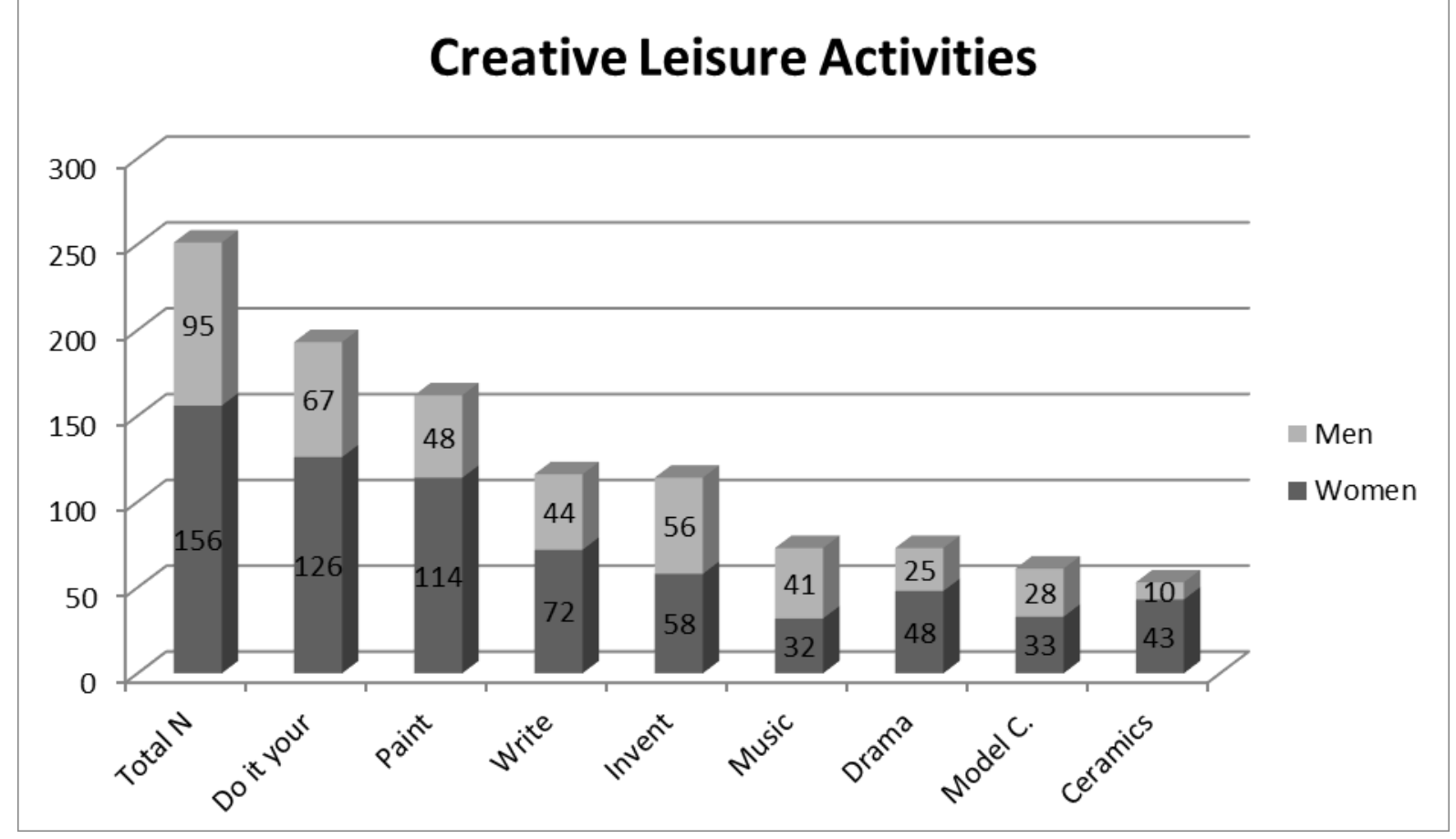

Figure 2. Weighted popularity of individual creative leisure activities

\section{Weighted Creative Leisure Activities}

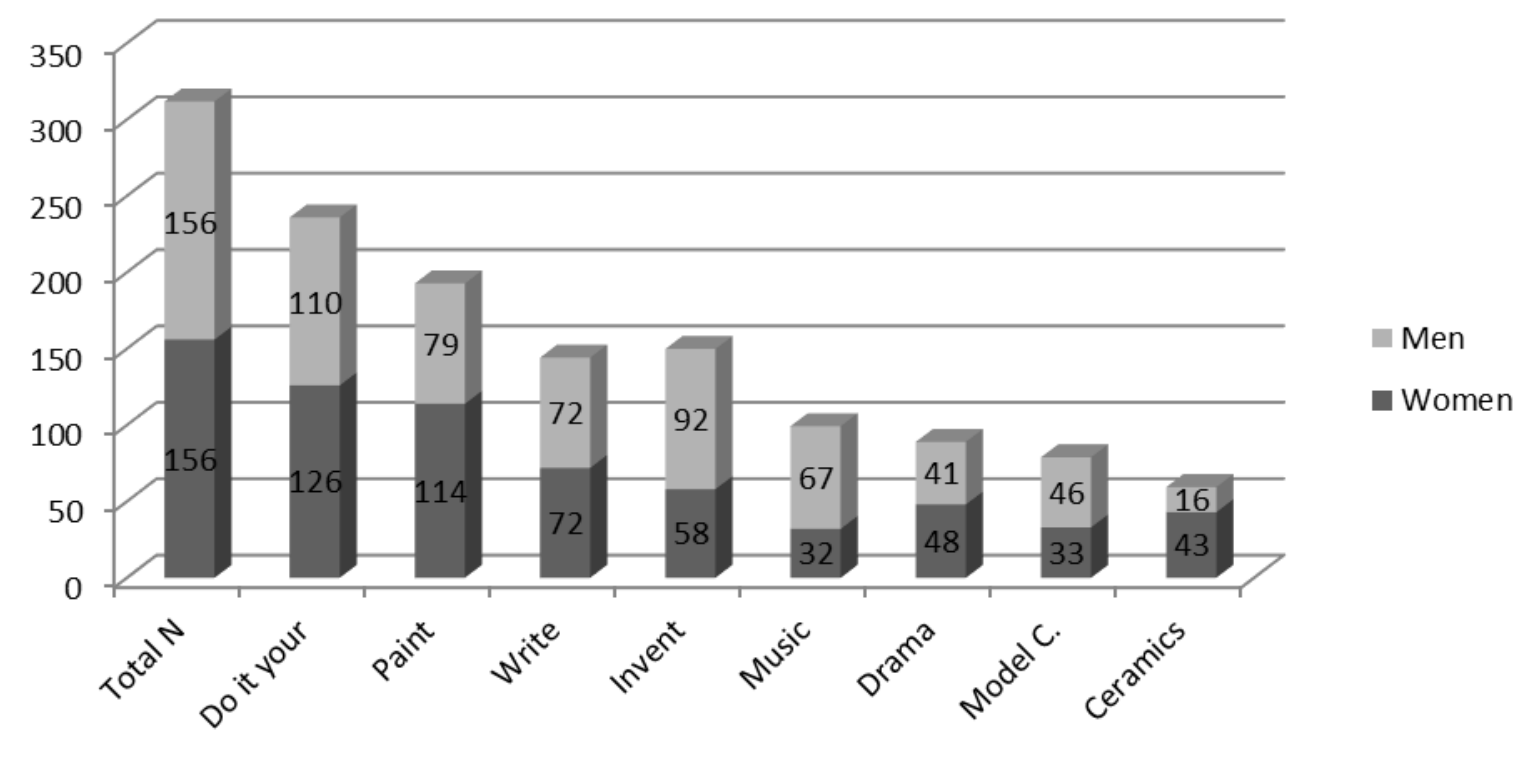


Figure 3. Real-life involvement in creative leisure activities according to field of study

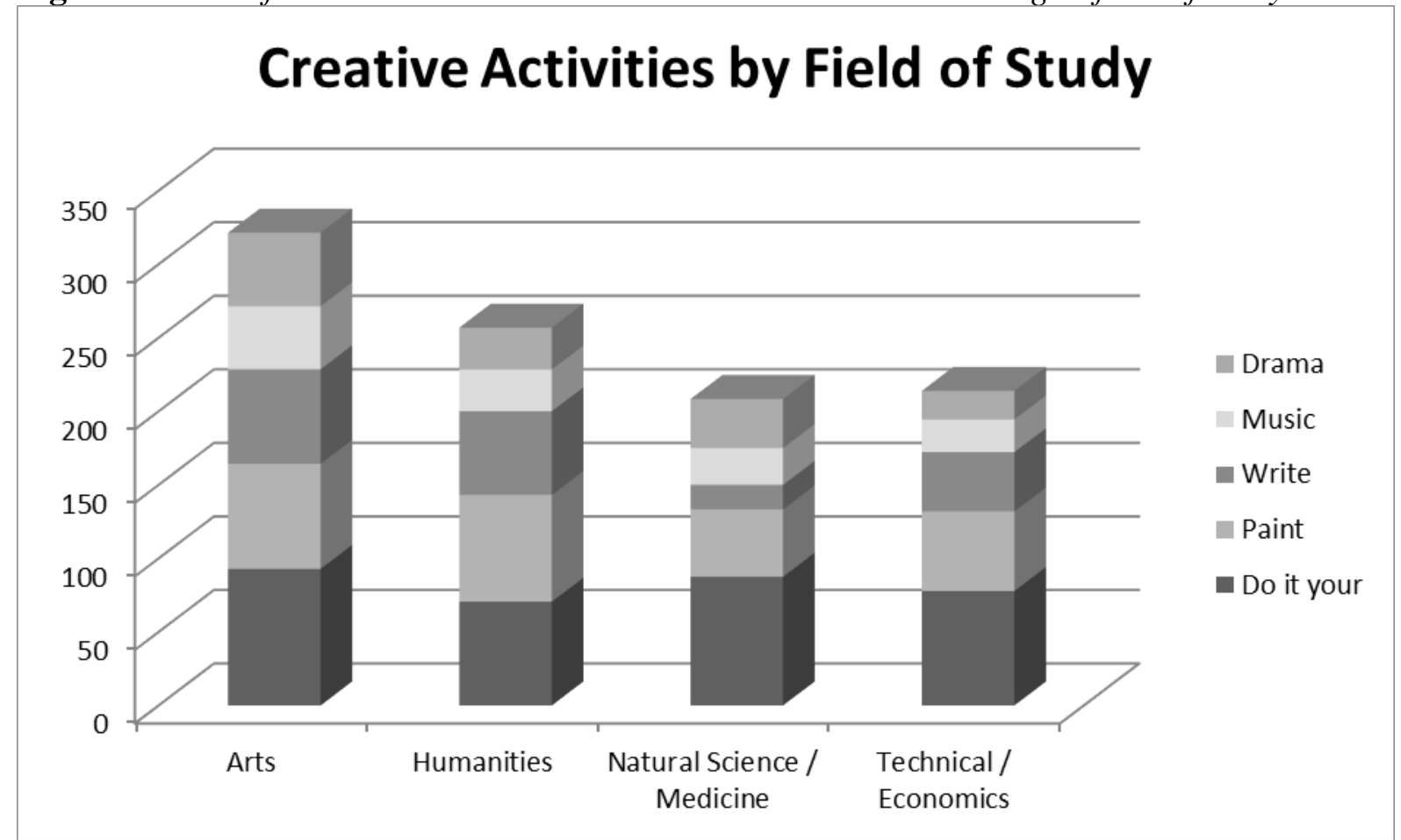

\section{EC and Field of Study}

When the relation of the ECI to field of study was explored, it seems to be related at least to some extent. A series of statistical tests (ANOVA and t-tests) conducted among university students and university graduates proved that arts students scored significantly higher on the ECI than other majors. Humanities scored significantly higher than technical/economic majors. The difference between humanities and natural sciences/medicine did not reach the threshold of significance, although students of humanities scored higher on the ECI than students of natural sciences/medicine majors (see Table 5).

The distribution of real-life involvement in creative leisure activities according to field of study is described in Figure 3. Each column presents percentages of students of different majors who conduct a particular leisure activity. The percentage was calculated from the total number of students in the discipline for each activity, therefore, it does not count $100 \%$ together. For easier orientation just the hobbies that were correlated with EC are presented.

\section{DISCUSSION}

The results of this study correspond with general assumption concerning different emotionality in art and humanities students in comparison to students of technical and economic majors. We provided new specific evidence in the given area, when investigating EC in relationship to university students' field of study. These results may extend the findings by Hartley and Greggs (1997) which pointed to the significant thinking differences in arts and science students. Also Furnham and Crump (2013) provided further confirmation of differences between art and science students by applying a combination of intelligence tests. Arts students scored higher on factors such as warmth, sensitivity, vigilance, tension or openness to change and lower on factors such as rule conscientiousness or perfectionism in comparison to science students. 
Arts students and graduates scored significantly higher on the ECI than other college majors in the present study. Further, humanities students and graduates scored significantly higher than technical and economic majors. The question arising from our results is, why? Inspiration for a possible causal explanation is suggested by e.g., Hartley and Greggs (1997), who stressed the key importance of the role of secondary school teachers on pupils' thinking and may function as a crucial factor for the future choice of college major. Teachers' personality including teaching style, how attractively they present their subject area as well as their charisma may promote students' interest in a given field of study. Although such interests are developed in the course of both primary and secondary education, secondary level may play a more important role because it directly precedes university studies.

An alternative reasoning accompanied the results of Furnham and Crump's study (2013) turn our attention to childhood: "Thus one may expect the school pupil who does better at English than Mathematics to favour languages and that their results are in part a function of the verbal vs numerical ability. Equally the social and emotional sensitivity of a pupil may lead them to find arts subjects like poetry, music or literary criticism more attractive than the arts which are perceived as cold and "boring"." (p. 154). These assumptions worked with emotional sensitivity as an important influence on the development of preferences for various subjects. It is reasonable to understand emotional sensitivity as an overlapping construct with EC in this context, because preferences for subjects may be formed not only by heightened perception of emotional content, but also by their subsequent processing and storage into the memory. Such processing may be closely related to students' emotional creative capacities.

Thus, EC, distinct from emotional intelligence, seems to be primarily determined socially via the influence of parents, teachers, and peers. This statement is inline also with the delimitation of EC provided by Runco (2007, see p. 121). EC is a learned ability, developed in society and can be seen as a specific adaptation tool or mechanism to cope effectively with various everyday's situations via creative management of one's own - and/or manipulation of societal - emotions.

Another point to discuss here is how stable personal characteristics, such as EC, influence the choice of college majors among students. To explain this issue, Holland's theory of vocational choice (Holland, 1997) has been widely used to investigate students' personality types (realistic, investigative, artistic, social, enterprising, conventional) (see Helson, 1996; Ludwig, 1998), e.g., in relation to the choice of specific college majors (Pike, 2006; Smart, Feldman, \& Ethington, 2000). It stressed the importance of students' socialization into the selected major's environment, which corresponded to the mentioned specific personality types. The question is whether students are sufficiently aware of their personal dispositions to choose a suitable major environment. This point could also influence our interpretation of results, because individual Holland's personality types may be related to different levels of various emotional traits. However, it would be speculative to estimate in more details which Holland's personality types are more, or less, emotionally creative.

Turning to the role of real-life involvement in creative leisure activities, our research was based on the frequency of practicing of various leisure activities in relation to the emotional creative capacities measured by the ECI. Going into more detail, we found five of seven proposed types of creative hobbies significantly correlated positively to the ECI score: (1) writing poems or prose, including blogs (significant on $p=.01$ ); (2) painting: drawing pictures or other fine art activities (significant on $p=.01$ ); (3) DIY: do-it-yourself (significant on $p=.01$ ); (4) drama: performing drama or dance improvisation (significant on $p=.05$ ); (5) music: composing music or music improvisation (significant on $p=.05$ ). Surprisingly, "producing original ceramics and sculpture" and "any kind of inventing" was not in correlation with the ECI score. If we try to find any differences between activities correlating and not correlating with the ECI score, items (1) to (5) with an exception of (3) are similar in 
their creative artistic emphasis. On the other hand, DIY abilities are distinctive in that the primary motivation for their practice is oriented toward material outputs for daily use. Let us briefly introduce the specific status of DIY in the Czech post-communist culture.

DIY products are traditionally appreciated by the family as well as by others in the Czech post-transitional society. DIY abilities are usually useful at home when repairing broken electrical appliances, furniture, by car maintenance and at lots of amateur creative handicraft activities at home. A significant part of the Czech population was used to building their family houses alone or with the reciprocal help of neighbors. This is partially a result of the burden of 40 years of communist totality (1948 - 1989), when particularly DIY activities at weekend houses were the only way of self-realization, while travel, not-officially approved music, drama or literature was forbidden. DIY products are usually made with high personal involvement and emotional concern. Thus, the Czech historical context may explain the relationship of DIY with ECI in the Czech population sample.

On the other hand, "producing original ceramics and sculpture" and "any kind of inventing" seem to be activities not demanding high levels of EC. We believe that inventing does not belong in the artistic area, although creativity must be definitely present in the inventing process. However, it is tenable to assume that inventing is much more dependent on some types of cognitive creative abilities than on emotional creative abilities.

The present study has several limitations. The total number of 251 respondents allowed us to apply statistical tests reasonably. However, when the respondents were divided into field of study categories, the load of arts and natural science/medicine categories were disproportionate in comparison to the others. This fact was difficult for statistical comparison of the mean ECI scores especially between the two low numbered categories. Nevertheless, additional nonparametric tests (Mann Whitney $U$ and Wilcoxon $\mathrm{W}$ ) proved the difference between arts and natural science. In respect to the results, we propose for further research to ensure a more balanced sample of respondents to verify the exceptional EC of arts students.

Furthermore, the influence of previous secondary school teachers on the students' choice of college majors was not controlled in the present research design. It represents an important factor that may be also included in the design exploring the role of creative capacities in the choice of college majors. Measuring preferences of secondary school subjects as well as the popularity of the subjects' teachers could be a contributing for possible follow-up research on EC and college majors in the future.

\section{Acknowledgements}

Many thanks to Karel Balcar and Vaclav Grepl for their support during the preparation of the research design. This publication was supported by the Ministry of Education, Youth and Sports - Institutional Support of the Long-term Development of Research Organizations (Charles Univ, Fac Human and Env Cetnter St 2015) and by the Grant Agency of the Czech Republic, project 14/36005S (Competence based innovation and quality enhancement in higher education for sustainable development).

\section{REFERENCES}

Abele, B. A. (1992). Positive and negative mood influences on creativity: Evidence for asymmetrical effects. Polish Psychological Bulletin, 23, 203-221.

Aguilar-Vafaie, M. E., \& Runco, M. A. (2008). Material rewards, artistic creativity, inkblot perception, and emotional functioning. Baltic Journal of Psychology, 9, 46-69.

Amabile, T. M. (1985). Motivation and creativity: Effects of motivational orientation on creative writers. Journal of Personality and Social Psychology, 48, 393-397. 
Averill, J. R., \& Thomas-Knowles, C. (1991). Emotional creativity. In K. T. Strongman (Ed.), International Review of Studies on Emotion (Vol. 1, pp. 269-299). London, England: Wiley.

Averill, J. R. (1999). Individual differences in emotional creativity: Structure and correlates. Journal of Personality, 67, 331-371.

Brackett, M. A. (2003). Conceptualizing and measuring the life-space and its relation to Openness to Experience. Unpublished doctoral dissertation, University of New Hampshire, Durham.

Charyton, C., \& Snelbecker, G. E. (2007). General, artistic and scientific creativity attributes of engineering and music students. Creativity Research Journal, 19, 213-225.

Cheung, C. K., Rudowicz, E., Yue, X., \& Kwan, A. S. F. (2003). Creativity of university students: What is the impact of field and year of study? Journal of Creative Behavior, 37, 42-63.

Fuchs, G. L., Kumar, V. K., \& Porter, J. (2007). Emotional creativity, alexithymia, and styles of creativity. Creativity Research Journal, 19, 233-245.

Furnham, A., Batey, M., Booth, T. W., Patel, V., \& Lozinskaya, D. (2011). Individual difference predictors of creativity in art and science students. Thinking Skills and Creativity, 6, 114-121.

Furnham, A., \& Crump, J. (2013). The sensitive, imaginative, articulate art student and conservative, cool, numerate science student: Individual differences in art and science students. Learning \& Individual Differences, 25, 150-155.

Gutbezahl, J., \& Averill, J. (1996). Individual differences in emotional creativity as manifested in words and pictures. Creativity Research Journal, 9, 327-337.

Hartley, J., \& Greggs, M. A. (1997). Divergent thinking in arts and science students: Contrary Imaginations at Keele revisited. Studies in Higher Education, 22, 93-97.

Helson, R. (1996). In search of creative personality. Creativity Research Journal, 9, 295-306.

Holland, J. L. (1997). Making vocational choices: A theory of vocational personalities and work environments (3rd ed.). Odessa, FL: Psychological Assessment Resources.

Humphreys, J. (2008). Emotional disposition and leadership preferences of American and Chinese MBA students. International Journal of Leadership Studies, 3, 162-180.

Ivcevic, Z., Brackett, M. A., \& Mayer, J. D. (2007). Emotional intelligence and emotional creativity. Journal of Personality, 75, 199-236.

Kumar, V. K., \& Holman, E. R. (1997). Creativity Styles Questionnaire-Revised. Unpublished psychological test, Department of Psychology, West Chester University, West Chester, PA.

Long, C. R., Seburn, M., Averill, J. R., \& More, T. A. (2003). Solitude experiences: Varieties, settings, and individual differences. Personality and Social Psychology Bulletin, 29, 578-583.

Ma, H. H. (2009). The effect size of variables associated with creativity: A meta-analysis. Creativity Research Journal, 21, 30-42.

Pike, G. (2006). Students' personality types, intended majors, and college expectations: Further evidence concerning psychological and sociological interpretations of Holland's theory. Research in Higher Education, 47, 801-822.

Runco, M. A. (2007). Creativity: Theories and themes: Research, development, and practice. Burlington, MA: Elsevier Academic Press.

Sánchez-Ruiz, M. J., Hernández-Torrano, D., Pérez-González, J. C., Batey, M. \& Petrides, K. V. (2011). The relationship between trait emotional intelligence and creativity across subject domains. Motivation \& Emotion, 35, 461-473.

Shames, V. A. (1994). Is there such a thing as implicit problem-solving? Unpublished doctoral dissertation. University of Arizona, Tuscon. 
Smart, J. C., Feldman, K. A., \& Ethington, C. A. (2000). Academic Disciplines: Holland's Theory and the Study of College Students and Faculty. Nashville, TN: Vanderbilt University Press.

Torrance, E. P. (1976). Tests de pensée créative [Torrance Test of Creative Thinking]. Paris, France: LesEditions du Centre de Psychologie Appliquée.

Zenasni, F., \& Lubart, T. I. (2008). Emotion-related traits moderate the impact of emotional state on creative performances. Journal of Individual Differences, 29, 157-167. 